\title{
SOURCE: Prediction Models for Overall Survival in Patients With Metastatic and Potentially Curable Esophageal and Gastric Cancer
}

\author{
Héctor G. van den Boorn, MSc'; Ameen Abu-Hanna, PhD²; Nadia Haj Mohammad, MD, PhD; \\ Maarten C.C.M. Hulshof, MD, PhD'; Suzanne S. Gisbertz, MD, PhD'; Bastiaan R. Klarenbeek, MD, PhD5; \\ Marije Slingerland, MD, PhD; ; Laurens V. Beerepoot, MD, PhD7; Tom Rozema, MD; Mirjam A.G. Sprangers, PhD; \\ Rob H.A. Verhoeven, $\mathrm{PhD}^{5,10}$; Martijn G.H. van Oijen, $\mathrm{PhD}^{1,10}$; \\ Koos H. Zwinderman, PhD ${ }^{11}$; and Hanneke W.M. van Laarhoven, MD, PhD
}

\section{ABSTRACT}

Background: Personalized prediction of treatment outcomes can aid patients with cancer when deciding on treatment options. Existing prediction models for esophageal and gastric cancer, however, have mostly been developed for survival prediction after surgery (ie, when treatment has already been completed). Furthermore, prediction models for patients with metastatic cancer are scarce. The aim of this study was to develop prediction models of overall survival at diagnosis for patients with potentially curable and metastatic esophageal and gastric cancer (the SOURCE study). Methods: Data from 13,080 patients with esophageal or gastric cancer diagnosed in 2015 through 2018 were retrieved from the prospective Netherlands Cancer Registry. Four Cox proportional hazards regression models were created for patients with potentially curable and metastatic esophageal or gastric cancer. Predictors, including treatment type, were selected using the Akaike information criterion. The models were validated with temporal cross-validation on their $\mathrm{C}$-index and calibration. Results: The validated model's C-index was 0.78 for potentially curable gastric cancer and 0.80 for potentially curable esophageal cancer. For the metastatic models, the c-indices were 0.72 and 0.73 for esophageal and gastric cancer, respectively. The $95 \%$ confidence interval of the calibration intercepts and slopes contain the values 0 and 1, respectively. Conclusions: The SOURCE prediction models show fair to good c-indices and an overall good calibration. The models are the first in esophageal and gastric cancer to predict survival at diagnosis for a variety of treatments. Future research is needed to demonstrate their value for shared decisionmaking in clinical practice.

J Natl Compr Canc Netw 2021;19(4):403-410 doi: $10.6004 /$ jnccn.2020.7631

See JNCCN.org for supplemental online content.

\section{Background}

Esophageal and gastric cancer are the eighth and fifth most common cancers worldwide, respectively. ${ }^{1,2}$ Both types of cancer have a high mortality rate due in part to the high prevalence of distant metastases at diagnosis $(\sim 20 \%-30 \%$ of patients with esophageal cancer and $\sim 30 \%-40 \%$ of patients with gastric cancer). ${ }^{2-4}$

Multiple treatment options are available for patients with metastatic or potentially curable disease. Potentially curable gastric and esophageal cancer can be treated with surgery with or without (neo)adjuvant chemo(radio) therapy. Potentially curable esophageal cancer can also be treated with definitive chemoradiotherapy. Metastatic disease is treated mainly with systemic therapy but also with best supportive care. ${ }^{5,6}$

However, even in the curative setting, outcome of these treatments is poor in esophageal and gastric cancer, with 5-year survival rates $<50 \%$, whereas treatment-related morbidity is high. ${ }^{7,8}$ Therefore, patient preferences and values should play a significant role in shared decision-making concerning treatment options. ${ }^{9}$ When deciding on treatment, it is therefore vital that patients are provided accurate and preferably personalized information about the risks and benefits of

\footnotetext{
${ }^{1}$ Department of Medical Oncology, Cancer Center Amsterdam, and ${ }^{2}$ Department of Medical Informatics, Amsterdam UMC, University of Amsterdam, Amsterdam; ${ }^{3}$ Department of Medical Oncology, University Medical Center Utrecht, Utrecht; ${ }^{4}$ Department of Surgery, Amsterdam UMC, University of Amsterdam, Amsterdam; ${ }^{5}$ Department of Surgery, Radboud University Medical Center, Nijmegen; ${ }^{6}$ Department of Medical Oncology, Leiden University Medical Center, Leiden; ${ }^{7}$ Department of Medical Oncology, Elisabeth Tweesteden Hospital, Tilburg; ${ }^{8}$ Department of Radiotherapy, Verbeeten Institute, Tilburg; ${ }^{9}$ Department of Medical Psychology, Amsterdam UMC, University of Amsterdam, Amsterdam; ${ }^{10}$ Department of Research \& Development, Netherlands Comprehensive Cancer Organization (IKNL), Utrecht; and ${ }^{11}$ Department of Clinical Epidemiology, Biostatistics and Bioinformatics, Amsterdam UMC, University of Amsterdam, Amsterdam, the Netherlands.
} 
the treatment trajectories, ideally based on prediction models. ${ }^{10,11}$

Several prediction models have been developed to predict risks and benefits in patients with esophageal and gastric cancer. ${ }^{12}$ However, these models are largely focused on the curative setting and predict survival after completion of a curative resection; they therefore cannot be used for clinical decision-making before the start of treatment, nor can they be used to compare different treatment options. Furthermore, prediction models for the metastatic setting are scarce.

We recently developed 2 models to predict survival in patients with metastatic esophageal or gastric cancer based on tumor, patient, and treatment characteristics. ${ }^{13}$ Although these models had good calibration and a fair C-index, some important information was not available at the time of development, such as HER2/neu status and WHO performance status, which would improve the models' performance. ${ }^{14,15}$ The aim of this study (the SOURCE study) is to create 2 new models to predict survival in patients with potentially curable esophageal or gastric cancer and to update our previously published models for patients with metastatic esophageal and gastric cancer.

\section{Methods}

This article adheres to the TRIPOD guidelines. ${ }^{16}$ According to the Central Committee on Research Involving Human Subjects, this type of study does not require approval from an ethics committee in the Netherlands. However, the study was approved by the Privacy Review Board of the Netherlands Cancer Registry (NCR; project code K17134).

\section{Dataset}

NCR data were used in the development and validation of the SOURCE prediction models. ${ }^{17}$ This nationwide population-based registry is prospectively maintained. Since 2015, additional potential predictors were added to the database. We therefore decided to include only patients diagnosed in 2015 through 2018 (the year with the last available data in the NCR) with a primary esophageal or gastric tumor. Patients with $\mathrm{cMl}$ disease were classified as having metastatic cancer, and patients with stage cT1-4a,xN0-3,xM0 disease were classified as having potentially curable disease. This classification was also used in previous studies. ${ }^{18,19}$ Patients with metastatic disease whose first metastasis was discovered $\geq 4$ days after treatment initiation were classified as having cM0 disease because they were diagnosed without any metastases.

Data from the NCR dataset were divided into 4 cohorts based on primary tumor location (esophageal vs gastric cancer) and cM stage (metastatic vs potentially curable cancer). The primary tumor was classified as esophageal cancer if the ICD-O topography code was C15.X or C16.0 (cardia) and as gastric cancer for C16.1-9. ${ }^{20}$ Four prediction models were created based on these 4 datasets. The follow-up period lasted until January 2019 for a maximum of 4-year follow-up for all patients.

Exclusion criteria included unknown vital status at the end of follow-up, unknown follow-up or survival of at most 14 days, primary cT0 or in situ tumor, and unknown tumor histology. For patients with multiple primary tumors, duplicates were removed and only the earliest entry per patient was retained. Patients with metastatic disease who had distant metastases confined to lymph nodes of the head and neck area were excluded from the analyses because they could be treated with curative intent (Figure 1).

\section{Development and Validation of the Models}

The methods for constructing the SOURCE prediction models were described in detail previously. ${ }^{13}$ In short, the following procedures were followed. First, a preliminary predictor selection was made for each cohort. Predictors were selected if they were available for $\geq 50 \%$ in the dataset, had $<50$ levels (for categorical variables only), and did not have the same values for all patients (and would therefore have been noninformative). Performance status, body mass index (BMI), American Society of Anesthesiologists performance status classification, HER2/neu status, and laboratory results (hemoglobin, creatinine, lactate dehydrogenase, albumin levels) were also included in the preliminary predictor selection, in contrast to the previous study, because these variables became available for patients diagnosed as of 2015. ${ }^{14,15}$ All predictors included in the SOURCE prediction models were determined at the time of diagnosis.

Next, a multivariate Cox proportional hazards regression model was created in each cohort, with overall survival as the outcome. ${ }^{21}$ Overall survival was measured from diagnosis to death or censored at the date of last follow-up. In contrast to the previous study, the present models do not include interaction terms. It was found that the interaction terms did not increase model performance (data not shown), and the interaction terms were removed to avoid overfitting. Initially, all predictors from the preliminary selection were included in the model, and multiple imputation with 10 iterations via chained equations (multivariate imputation by chained equations [MICE]) was used to handle missing data. ${ }^{22}$ A bidirectional predictor selection using the Akaike information criterion (AIC) was used to create a final predictor selection in each cohort. ${ }^{23}$ From the resulting 


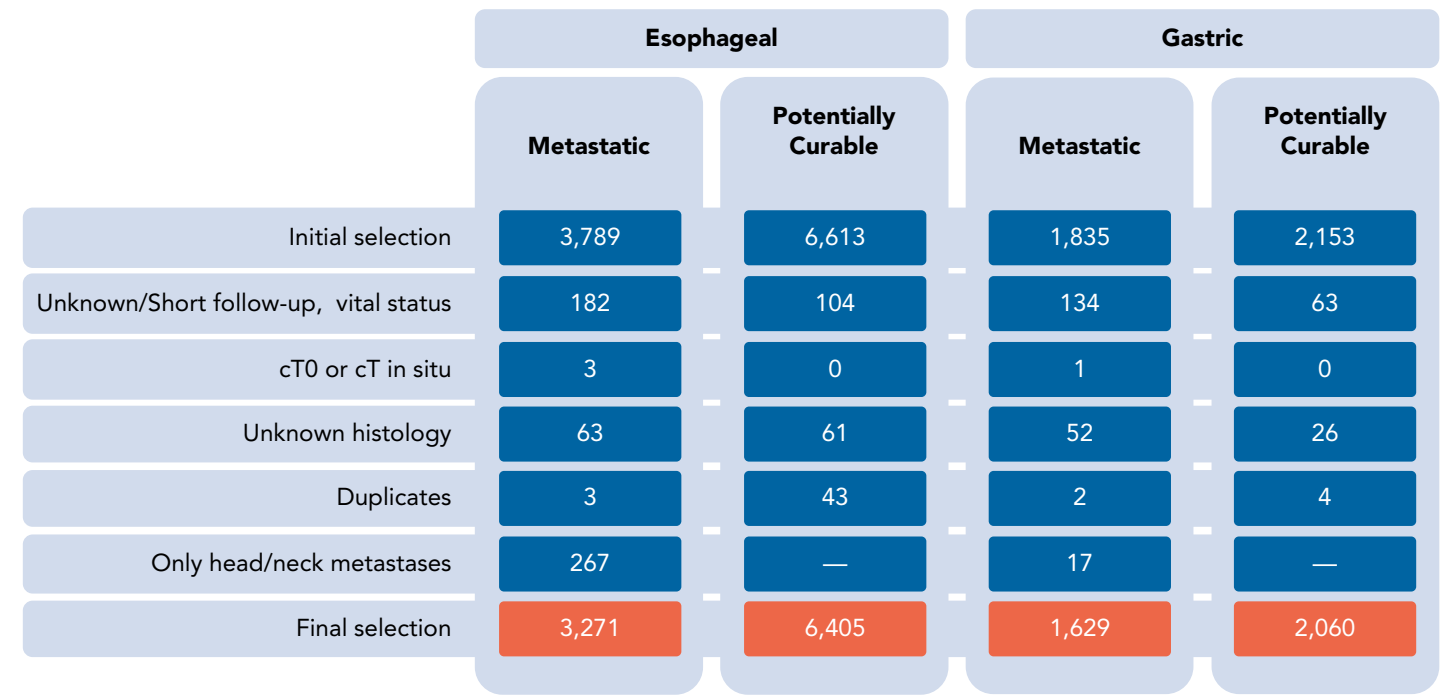

Figure 1. Patient inclusion flowchart. The 4 initial cohort sizes in the Netherlands Cancer Registry and the number of patients excluded are shown. The final selection was used in creating the SOURCE prediction models.

models, the C-index, calibration slope, intercept, and deviance were obtained. The C-index is a measure of discrimination and ranges from 0.5 (not able to discriminate survival outcome among individuals) to 1 (perfect discrimination).$^{24}$ The calibration refers to the concordance between predicted and observed survival. With a perfect calibration, the calibration intercept is 0 , and the calibration slope is $1 .^{24}$ The calibration deviance refers to the mean absolute difference between predicted and observed survival. ${ }^{25} \mathrm{All}$ models were developed using the rms (regression modeling strategy) package in the RStudio environment with $\mathrm{R}$ version 3.6.1 (R Foundation for Statistical Computing).

To test the robustness of the models, an internalexternal temporal cross-validation scheme was used. ${ }^{26}$ Within this framework, the aforementioned model development was used to create models for patients diagnosed in earlier years, after which the model was evaluated based on patients in later years. This mimics the way in which models are evaluated when used in real life and reflects model performance behavior in the face of potential population drift over time. This method allows the simulation of a true temporal external validation while using the entire available dataset. ${ }^{26}$ This cross-validation is explained in more detail in our previous publication. ${ }^{13}$ First, data from the earliest diagnosis year (2015) were used to create prediction models. The model's performance was then evaluated based on patients diagnosed in the subsequent year (2016). This process was then repeated for later diagnosis years; the training cohort included 2015 through 2016 and was validated based on the 2017 cohort, after which the model was trained on patients diagnosed in 2015 through 2017 and validated based on patients diagnosed in 2018. The performance statistics were pooled to obtain a cross-validated estimation of the model performance. To summarize, a Cox proportional hazards regression model was created for each cohort based on all available data, and a meta-analysis of crossvalidated performance statistics was calculated to determine the model quality.

\section{Results}

Table 1 provides an overview of patient characteristics for the included cohort. Additional patient characteristics are provided in supplemental eTable 1 (available with this article at JNCCN.org). Kaplan-Meier curves for the 4 cohorts are provided in supplemental eFigure 1.

A complete overview of the parameters of the 4 SOURCE models is provided in supplemental eTables 2 through 5 . These tables show the final predictor selection and the associated hazard ratios for each parameter in the multivariate Cox proportional hazards regression models. Table 2 shows an overview of the selected parameters in each prediction model.

The SOURCE models are also displayed graphically as nomograms in supplemental eFigures $2-5 .{ }^{27}$ In a nomogram, the value of each predictor (eg, the weight of the patient) is marked on its scale and then associated with a number of points that can be read from the top scale. The sum of all points can then be placed in the bottom scale, after which the survival estimate is determined. The nomograms provide survival estimates at 6 and 12 months for metastatic cancers and at 1 through 4 years for potentially curable cancers. 
Table 1. Characteristics of Included Patients

\begin{tabular}{|c|c|c|c|c|}
\hline & \multicolumn{2}{|c|}{$\begin{array}{c}\text { Esophageal Cancer } \\
n(\%)\end{array}$} & \multicolumn{2}{|c|}{$\begin{array}{c}\text { Gastric Cancer } \\
\text { n (\%) }\end{array}$} \\
\hline & Metastatic & Potentially Curable & Metastatic & Potentially Curable \\
\hline OS, median (IQR), mo & $5.3(5.0-5.6)$ & $22.7(21.7-23.8)$ & $4.3(4.0-4.6)$ & $22.8(21.2-25.8)$ \\
\hline Age, mean (SD), y & $67.40(10.38)$ & $69.59(10.49)$ & $68.95(12.20)$ & $72.19(12.19)$ \\
\hline Female & $703(21.5)$ & $1,762(27.5)$ & $642(39.4)$ & 822 (39.9) \\
\hline Weight, mean (SD), kg & $77.26(16.03)$ & $77.80(17.05)$ & 73.69 (15.32) & $73.96(15.31)$ \\
\hline BMI, mean (SD), kg/m² & $25.10(4.46)$ & $25.59(4.74)$ & $24.94(4.57)$ & $25.26(4.51)$ \\
\hline Missing & $1,517(46.4)$ & $2,410(37.6)$ & $763(46.8)$ & $913(44.3)$ \\
\hline 1 & $906(27.7)$ & $1,900(29.7)$ & $397(24.4)$ & $518(25.1)$ \\
\hline 2 & $355(10.9)$ & $521(8.1)$ & $181(11.1)$ & $146(7.1)$ \\
\hline$\geq 3$ & $192(5.9)$ & $195(3.0)$ & $100(6.1)$ & $72(3.5)$ \\
\hline \multicolumn{5}{|l|}{ cT stage } \\
\hline 1 & $16(0.5)$ & $347(5.4)$ & $3(0.2)$ & $103(5.0)$ \\
\hline 2 & $1,186(36.3)$ & $1,891(29.5)$ & $453(27.8)$ & $773(37.5)$ \\
\hline 3 & $964(29.5)$ & $3,154(49.2)$ & $353(21.7)$ & $483(23.4)$ \\
\hline 4 & $240(7.3)$ & $109(1.7)$ & $281(17.2)$ & $91(4.4)$ \\
\hline$x$ & $865(26.4)$ & $904(14.1)$ & $539(33.1)$ & $610(29.6)$ \\
\hline Best supportive care & $701(21.4)$ & - & $683(41.9)$ & - \\
\hline CRT & $67(2.0)$ & - & - & - \\
\hline Chemotherapy & $999(30.5)$ & - & $587(36.0)$ & - \\
\hline Other & $97(3.0)$ & - & $188(11.5)$ & - \\
\hline RT (metastasis) & $219(6.7)$ & - & - & - \\
\hline RT (primary tumor) & $954(29.2)$ & - & $108(6.6)$ & - \\
\hline Stent & $234(7.2)$ & - & $63(3.9)$ & - \\
\hline
\end{tabular}

(continued on next page)

The performance statistics of all models are shown in Table 3. These results show an overall good calibration in all models. The $95 \%$ confidence intervals of the slopes and those of the intercepts include 1 and 0 , respectively. The calibration deviance shows average prediction errors of $1 \%$ to $5 \%$. The c-indices are 0.72 for metastatic cancers and are even higher for potentially curable cancers, with magnitudes of 0.78 and 0.80 .
Additional calibration plots are displayed in supplemental eFigure 6 and show the correspondence between predicted and observed survival per year cohort of validation.

\section{Discussion}

The primary aim of this study was to create prediction models for overall survival in patients with potentially curable and metastatic esophageal or gastric cancer. 


\begin{tabular}{|c|c|c|c|c|}
\hline & \multicolumn{2}{|c|}{$\begin{array}{c}\text { Esophageal Cancer } \\
\mathbf{n}(\%)\end{array}$} & \multicolumn{2}{|c|}{$\begin{array}{c}\text { Gastric Cancer } \\
\mathbf{n}(\%)\end{array}$} \\
\hline & Metastatic & Potentially Curable & Metastatic & Potentially Curable \\
\hline \multicolumn{5}{|l|}{ Treatment } \\
\hline Best supportive care & - & $529(8.3)$ & - & $405(19.7)$ \\
\hline CRT (high-dose) & - & $861(13.4)$ & - & - \\
\hline CRT (low-dose) & - & $557(8.7)$ & - & - \\
\hline Chemotherapy & - & $81(1.3)$ & - & $112(5.4)$ \\
\hline Endoscopic resection & - & $362(5.7)$ & - & $61(3.0)$ \\
\hline NACRT + surgery & - & $2,566(40.1)$ & - & - \\
\hline NACT + surgery & - & $153(2.4)$ & - & $310(15.0)$ \\
\hline Other & - & $227(3.5)$ & - & $79(3.8)$ \\
\hline Perioperative chemotherapy & - & $132(2.1)$ & - & $471(22.9)$ \\
\hline RT & - & $716(11.2)$ & - & $77(3.7)$ \\
\hline Resection & - & 221 (3.5) & - & $545(26.5)$ \\
\hline
\end{tabular}

Patient characteristics are stratified by tumor location and metastatic versus potentially curable disease. $\mathrm{cT}$ stage, $\mathrm{cN}$ stage, and differentiation grade are defined according to the TNM staging system of the 8th edition of the AJCC Cancer Staging Manual. The initial palliative treatment is the first treatment that a patient received after diagnosis.

Abbreviations: BMI, body mass index; IQR, interquartile range; NACRT, neoadjuvant chemoradiotherapy; NACT, neoadjuvant chemotherapy; OS, overall survival; $\mathrm{RT}$, radiotherapy.

The SOURCE models are based on a large national cohort of patients diagnosed in recent years and form a complete set of models for use in upper gastrointestinal cancers. In contrast with other previously developed prediction models, the SOURCE models stand out due to their applicability to the full range of patients with curative and palliative esophageal and gastric cancer and are to be used before the start of treatment. ${ }^{28-30}$ Moreover, they are the first esophageal and gastric cancer prediction models that include treatment as a predictor.

The robustness and generalizability of the models were considered during model development. The AIC method was used to automatically guide the predictor selection. Missing data were handled with multiple imputations (MICE). With this method, the prediction models are based on multiple datasets in which the missing values were imputed. The number of patients with at most 2 missing variables is 10.490 (78.5\%). Because multiple imputations were made, the uncertainty of each individual imputation is taken into account. ${ }^{31}$ This has the benefit of reducing bias compared with other methods, such as complete-case analysis. ${ }^{31}$ To investigate the effect of overfitting, the models were also analyzed with an internal-external temporal crossvalidation. With this method, it is possible to simulate a temporal validation of the models that helps to examine how well the models might work with patient cohorts diagnosed in later years, provided they are more or less comparable. ${ }^{26}$ This is especially relevant when developing models for clinical practice, because predictions will be made for patients diagnosed after the model has been developed.

The performance measures of the SOURCE models are similar for the complete model and for the internalexternal cross-validation, indicating a lack of overfit. The c-indices of the potentially curable models are $>0.75$ (the average C-index of other prediction models for esophageal and gastric cancer models), whereas the metastatic models had a C-index of 0.72 to 0.73 , which can be considered fair. ${ }^{12}$ There is also a good calibration slope and intercept for all models.

The presented metastatic models represent an update of our previously published models. ${ }^{13}$ Model updating is an important part in the lifecycle of a prediction model. ${ }^{32}$ The current models significantly differ from the previous models. First, the current models are developed based on more recent cohorts (2015-2018) than the previous models (2005-2015). In recent years, the NCR has extended its data collection to incorporate additional variables that could potentially be included as predictors and improve model performance. Indeed, WHO performance status and HER2/neu status are now included in the SOURCE models, as are BMI and albumin, hemoglobin, lactate dehydrogenase, and creatinine levels. ${ }^{14,15}$ Second, parameter interaction terms were removed from the models; this had no significant effect on model performance, and further decreases the potential of overfitting. The resulting updated models showed stable or even increased performance statistics, and the $\mathrm{C}$-index of the gastric cancer model 
Table 2. Overview of Selected Parameters in Each Prediction Model

\begin{tabular}{|c|c|c|c|c|}
\hline & \multicolumn{2}{|c|}{ Esophageal Cancer } & \multicolumn{2}{|c|}{ Gastric Cancer } \\
\hline Age & $x$ & $x$ & $x$ & $x$ \\
\hline $\mathrm{BMI}^{\mathrm{a}}$ & $\mathrm{x}$ & $\mathrm{x}$ & - & $x$ \\
\hline WHO performance status ${ }^{a}$ & $\mathrm{x}$ & - & $\mathrm{x}$ & - \\
\hline Hemoglobin $^{a}$ & - & $\mathrm{x}$ & $\mathrm{x}$ & - \\
\hline Lactate dehydrogenase ${ }^{a}$ & $x$ & $x$ & $x$ & $x$ \\
\hline Creatinine $^{a}$ & $x$ & - & - & - \\
\hline cT stage & $x$ & $\mathrm{x}$ & $x$ & $x$ \\
\hline $\mathrm{cN}$ stage & $\mathrm{x}$ & $\mathrm{x}$ & - & $x$ \\
\hline HER2 status ${ }^{a}$ & $\mathrm{x}$ & - & - & - \\
\hline Only distant lymph node metastasis & $x$ & - & - & - \\
\hline Liver metastasis & - & - & $\mathrm{x}$ & - \\
\hline Peritoneal metastasis & $x$ & - & - & - \\
\hline Number of metastatic sites & $x$ & - & $x$ & - \\
\hline Initial treatment & $x$ & - & $x$ & - \\
\hline Treatment & - & $x$ & - & $x$ \\
\hline
\end{tabular}

Abbreviation: BMI, body mass index.

aParameters were not available in the previous SOURCE models due to high missing rates.

increased from 0.68 to 0.73 . The model calibration demonstrates results in the updated models similar to those of the previous SOURCE models.

Some limitations of the SOURCE models should be mentioned. Patients were included as of 2015, implying a relatively short follow-up period, particularly for the cohorts with potentially curable disease. In this case, it was not possible to increase the follow-up to 5 years. In future models, a longer follow-up will be available, allowing predictions over a longer period of time for curative cohorts.

\section{Table 3. SOURCE Model Performance Statistics}

\begin{tabular}{|c|c|c|c|c|}
\hline & \multicolumn{2}{|c|}{ Metastatic } & \multicolumn{2}{|c|}{ Potentially Curable } \\
\hline & Complete Modela & Internal-External Validation ${ }^{\mathbf{b}}$ & Complete Modela & Internal-External Validation ${ }^{\mathbf{b}}$ \\
\hline \multicolumn{5}{|l|}{ Esophageal cancer } \\
\hline C-Index (95\% Cl) & 0.74 (0.72 to 0.75$)$ & 0.72 (0.71 to 0.74$)$ & 0.79 (0.78 to 0.80$)$ & $0.80(0.75$ to 0.84$)$ \\
\hline Calibration intercept $(95 \% \mathrm{Cl})$ & 0.02 (0.01 to 0.02 ) & $0.01(-0.02$ to 0.04$)$ & $0.05(0.05$ to 0.06$)$ & $-0.08(-0.26$ to 0.10$)$ \\
\hline Calibration slope $(95 \% \mathrm{Cl})$ & 0.96 (0.96 to 0.97$)$ & 0.97 (0.90 to 1.04$)$ & 0.94 (0.93 to 0.94$)$ & $1.11(0.88$ to 1.35$)$ \\
\hline Calibration deviance $(95 \% \mathrm{Cl})$ & 0.01 (0.01 to 0.01$)$ & 0.01 (0.01 to 0.02 ) & 0.03 (0.02 to 0.03$)$ & 0.04 (0.03 to 0.07$)$ \\
\hline \multicolumn{5}{|l|}{ Gastric cancer } \\
\hline C-Index $(95 \% \mathrm{Cl})$ & 0.73 (0.71 to 0.74$)$ & 0.72 (0.69 to 0.75$)$ & 0.78 (0.76 to 0.80$)$ & 0.78 (0.74 to 0.82$)$ \\
\hline Calibration intercept $(95 \% \mathrm{Cl})$ & $-0.01(-0.01$ to -0.01$)$ & $-0.04(-0.13$ to 0.05$)$ & 0.01 (0.01 to 0.02 ) & $-0.05(-0.15$ to 0.05$)$ \\
\hline Calibration slope $(95 \% \mathrm{Cl})$ & 1.03 (1.03 to 1.03$)$ & 1.09 (0.96 to 1.22$)$ & $0.99(0.99$ to 1.00$)$ & 1.04 (0.90 to 1.18$)$ \\
\hline Calibration deviance $(95 \% \mathrm{Cl})$ & 0.01 (0.01 to 0.01 ) & 0.03 (0.02 to 0.04$)$ & 0.01 (0.01 to 0.01$)$ & $0.04(0.03$ to 0.06$)$ \\
\hline
\end{tabular}

${ }^{a}$ Complete model statistics refer to the statistics obtained when creating and testing the final prediction model using all available cohort data.

bValidation statistics refer to the pooled values of all internal-external validation folds as described in the "Methods" section of text. 


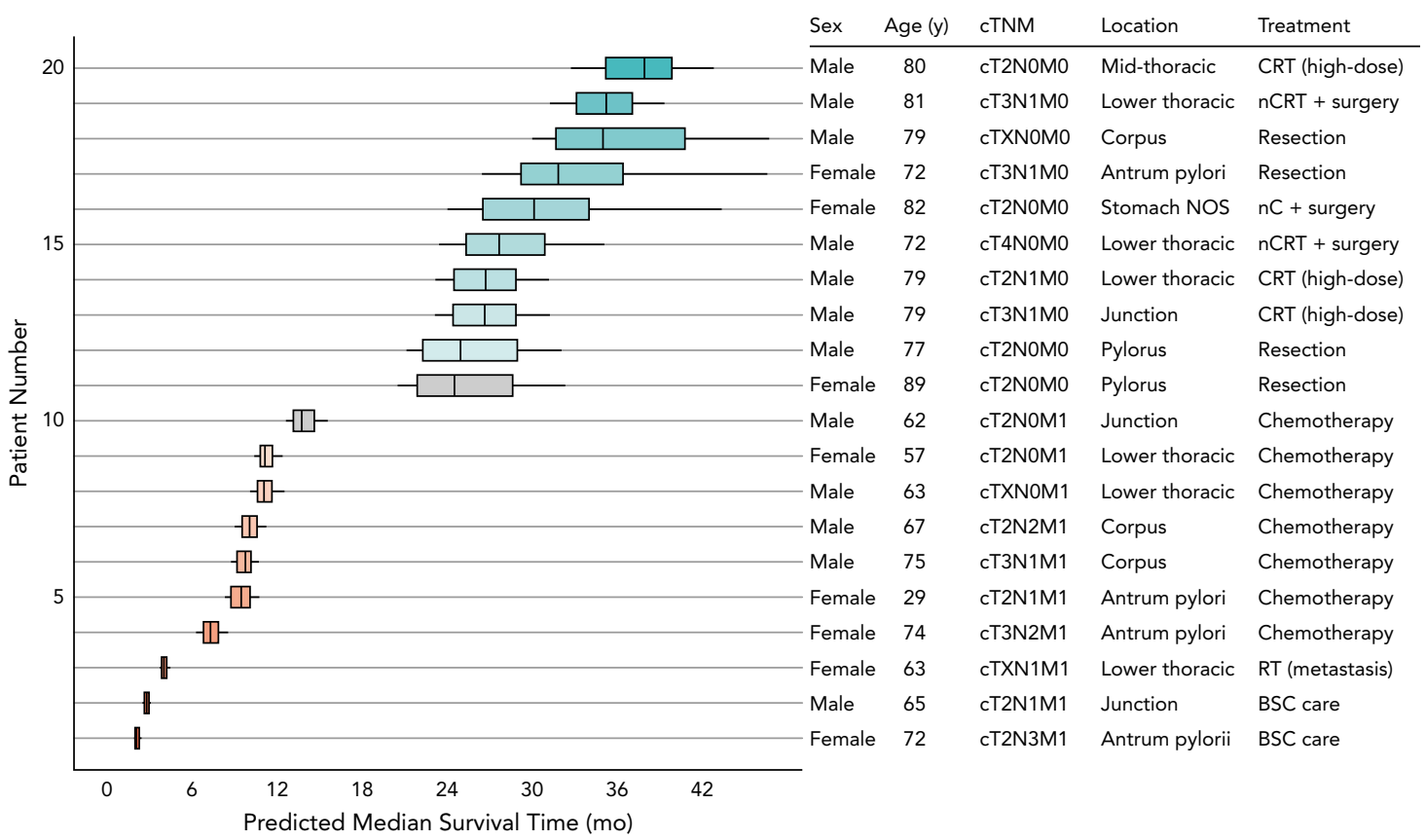

Figure 2. Individual predictions made by the SOURCE models. The vertical line within each bar represents the predicted median survival for a random selection of patients. The bars show the $50 \%$ confidence interval, and the lines show the $80 \%$ confidence interval. The table on the right shows a selection of patient characteristics used for the predictions.

Abbreviations: BSC, best supportive care; CRT, chemoradiotherapy; $\mathrm{nC}$, neoadjuvant chemotherapy; $\mathrm{nCRT}$, neoadjuvant chemoradiotherapy; NOS, not otherwise specified; RT, radiotherapy.

Another limitation is that information about treatment intent is not included in the NCR because it includes only the treatments patients actually received. For example, patients who intended to receive a neoadjuvant chemotherapy and surgery but did not advance to surgery because of clinical deterioration are classified as having received definitive chemotherapy. Predictions for definitive chemotherapy, for example, are therefore based on patients who intended to undergo definitive chemotherapy and on those who did not proceed to surgery after neoadjuvant treatment, which are clinical situations with likely different survival estimates. Furthermore, limited treatment details in the NCR led to broad treatment categories, as shown in supplemental eTable 1. These limitations should be considered when using the SOURCE models.

In addition, these models are based solely on a Dutch population, which may impact the generalizability of this study. External validation should be performed to further determine the robustness of the SOURCE models and applicability to other populations of patients with esophageal and gastric cancer. ${ }^{26}$ For this undertaking, it is vital to take into consideration the comparability of cohorts with respect to, for example, tumor histology and primary tumor origin. ${ }^{33}$

The main strength of the SOURCE models lies in their clinical applicability. SOURCE forms a complete set of models that cover both potentially curable and metastatic esophageal and gastric cancer. The predictors used in the models are readily available in standard clinical care and do not require additional testing. The inclusion of treatment as a model parameter makes it possible to compare the survival for various relevant treatment options, which can help with shared decision-making. ${ }^{11}$ Figure 2 illustrates how the SOURCE models can be used to create predictions. The median predicted survival and confidence intervals are displayed for various patients with metastatic and potentially curable disease. It is also possible to compare the survival for various treatments, although one must be aware that not all treatments are relevant for each patient.

\section{Conclusions}

Currently, predictions can be made using the nomograms provided in supplemental eFigure 2. Although useful, these nomograms are not suitable for informing patients, and graphs or icon arrays should be used when informing patients about treatment outcomes. ${ }^{34}$ The SOURCE models will be tested extensively in a clinical trial (ClinicalTrials.gov identifier: NCT04232735) to examine their effect on shared decision-making. The SOURCE models will become available through a web interface (https:// source.amc.nl/) that is currently under development and the subject of a clinical trial, and they are therefore not accessible yet to the general public. This web interface will be used to facilitate the use of the prediction models and to display the predictions with user-friendly visualizations. 
Submitted May 18, 2020; accepted for publication July 30, 2020.

Published online February 26, 2021.

Author contributions: Study concept and design: van den Boorn, AbuHanna, Sprangers, Zwinderman, van Laarhoven. Data acquisition, analysis, or interpretation: All authors. Statistical analysis: van den Boorn, Verhoeven, Zwinderman, van Laarhoven. Drafting of manuscript: van den Boorn, AbuHanna, Sprangers, Zwinderman, van Laarhoven. Critical revision: All authors. Administrative, technical, or material support: Abu-Hanna, Haj Mohammad, Hulshof, Gisbertz, Klarenbeek, Slingerland, Beerepoot, Rozema, Sprangers, Verhoeven, van Oijen, Zwinderman, van Laarhoven. Supervision: Abu-Hanna, Sprangers, Zwinderman, van Laarhoven. Obtained funding: van Laarhoven.

Disclosures: Dr. Abu-Hanna has disclosed that he is a consultant/adviser for ExpertDoc. Dr. Haj Mohammad has disclosed that she receives grant/research support from Servier, and consulting fees from Bristol-Myers Squibb Brazil Celgene, Lilly, and Merck Sharp \& Dohme. Dr. Verhoeven has disclosed that he receives grant/research support from Bristol-Myers Squibb. Dr. van Oijen has disclosed that he receives grant/research support from Amgen, Lilly, Nordic Bioscience, Roche, and Servier. Dr. van Laarhoven has disclosed that she receives honoraria from Lilly/lmClone; grant/research support from Baye
Schering Pharma, Bristol-Myers Squibb, Celgene, Janssen-Cilag, Lilly, Merck Sharp \& Dohme, Nordic Group, Philips Healthcare, Roche, and Servier consulting fees from AstraZeneca; and is a consultant/adviser for Bristol-Myers Squibb, Lilly/lmClone, Nordic Group, and Servier. The remaining authors have disclosed that they have not received any financial consideration from any person or organization to support the preparation, analysis, results, or discussion of this article.

Funding: This work was supported by the Dutch Cancer Society (UVA 2014 7000).

Disclaimer: The funder had no role in the design and conduct of the study; the collection, management, analysis, and interpretation of the data; the preparation, review, or approval of the manuscript; or the decision to submit the manuscript for publication.

Correspondence: Hanneke W.M. van Laarhoven, MD, PhD, PhD, Department of Medical Oncology, Amsterdam University Medical Centers, Meibergdreef 9; F4-224, 1105 AZ Amsterdam, the Netherlands.

Email: h.vanlaarhoven@amsterdamumc.nl

\section{References}

1. Arnold M, Soerjomataram I, Ferlay J, et al. Global incidence of oesophageal cancer by histological subtype in 2012. Gut 2015;64:381-387.

2. Ferlay J, Soerjomataram I, Dikshit $R$, et al. Cancer incidence and mortality worldwide: sources, methods and major patterns in GLOBOCAN 2012. Int J Cancer 2015;136:E359-386.

3. Napier KJ, Scheerer M, Misra S. Esophageal cancer: a review of epidemiology, pathogenesis, staging workup and treatment modalities. World J Gastrointest Oncol 2014;6:112-120.

4. Riihimäki $M$, Hemminki $A$, Sundquist $K$, et al. Metastatic spread in patients with gastric cancer. Oncotarget 2016;7:52307-52316.

5. Smyth EC, Verheij M, Allum W, et al. Gastric cancer: ESMO clinical practice guidelines for diagnosis, treatment and follow-up. Ann Oncol 2016;27(Suppl 5):v38-49.

6. Lordick F, Mariette C, Haustermans K, et al. Oesophageal cancer: ESMO clinical practice guidelines for diagnosis, treatment and follow-up. Ann Oncol 2016;27(Suppl 5):v50-57

7. Gavin AT, Francisci S, Foschi R, et al. Oesophageal cancer survival in Europe: a EUROCARE-4 study. Cancer Epidemiol 2012;36:505-512.

8. van den Ende T, Abe Nijenhuis FA, van den Boorn HG, et al. COMplot, a graphical presentation of complication profiles and adverse effects for the curative treatment of gastric cancer: a systematic review and metaanalysis. Front Oncol 2019;9:684

9. Barry MJ, Edgman-Levitan S. Shared decision making-pinnacle of patient-centered care. N Engl J Med 2012;366:780-781.

10. Vickers AJ. Prediction models in cancer care. CA Cancer J Clin 2011;61: 315-326.

11. Henselmans I, Van Laarhoven HWM, Van der Vloodt J, et al. Shared decision making about palliative chemotherapy: a qualitative observation of talk about patients' preferences. Palliat Med 2017;31:625-633.

12. van den Boorn HG, Engelhardt EG, van Kleef J, et al. Prediction models for patients with esophageal or gastric cancer: a systematic review and meta-analysis. PLoS One 2018;13:e0192310.

13. van den Boorn HG, Abu-Hanna A, Ter Veer E, et al. SOURCE: a registrybased prediction model for overall survival in patients with metastatic oesophageal or gastric cancer. Cancers (Basel) 2019;11:187.

14. Chan DSY, Twine CP, Lewis WG. Systematic review and meta-analysis of the influence of HER2 expression and amplification in operable oesophageal cancer. J Gastrointest Surg 2012;16:1821-1829.

15. Yates JW, Chalmer B, McKegney FP. Evaluation of patients with advanced cancer using the Karnofsky performance status. Cancer 1980;45:2220-2224

16. Collins GS, Reitsma JB, Altman DG, et al. Transparent Reporting of a multivariable prediction model for Individual Prognosis or Diagnosis (TRIPOD): the TRIPOD statement. Ann Intern Med 2015;162:55-63.

17. Netherlands Comprehensive Cancer Organisation (IKNL). IKNL and the NCR. Accessed November 10, 2020. Available at: https://www.iknl.nl/en
18. van Putten M, Verhoeven RHA, van Sandick JW, et al. Hospital of diagnosis and probability of having surgical treatment for resectable gastric cancer. Br J Surg 2016;103:233-241.

19. van der Sluis PC, van der Horst S, May AM, et al. Robot-assisted minimally invasive thoracolaparoscopic esophagectomy versus open transthoracic esophagectomy for resectable esophageal cancer: a randomized controlled trial. Ann Surg 2019;269:621-630.

20. Fritz A, Percy $C$, Jack $A$, et al. International Classification of Diseases for Oncology, 3rd ed. Geneva, Switzerland: World Health Organization; 2000

21. Fox J, Weisberg S. Cox proportional-hazards regression for survival data in $\mathrm{R}$. An appendix to an $\mathrm{R}$ companion to applied regression, second edition. Accessed November 10, 2020. Available at: https://citeseerx.ist.psu.edu/ viewdoc/download?doi=10.1.1.459.4496\&rep=rep1\&type =pdf

22. van Buuren S, Groothuis-Oudshoorn K. MICE: Multivariate Imputation by Chained Equations in R. J Stat Softw 2011;45:1-67.

23. Bozdogan $\mathrm{H}$. Model selection and Akaike's information criterion (AIC): the general theory and its analytical extensions. Psychometrika 1987;52:345-370.

24. Steyerberg EW, Vickers AJ, Cook NR, et al. Assessing the performance of prediction models: a framework for traditional and novel measures. Epidemiology 2010;21:128-138

25. Gerds TA, Schumacher M. Consistent estimation of the expected Brier score in general survival models with right-censored event times. Biom J 2006:48:1029-1040.

26. Steyerberg EW, Harrell FE Jr. Prediction models need appropriate internal, internal-external, and external validation. J Clin Epidemiol 2016;69:245-247.

27. Kattan MW, Marasco J. What is a real nomogram? Semin Oncol 2010;37:23-26.

28. Hagens ERC, Feenstra ML, Eshuis WJ, et al. Conditional survival after neoadjuvant chemoradiotherapy and surgery for oesophageal cancer. $\mathrm{Br}$ J Surg 2020;107:1053-1061.

29. Woo Y, Son T, Song K, et al. A novel prediction model of prognosis after gastrectomy for gastric carcinoma: development and validation using Asian databases. Ann Surg 2016;264:114-120.

30. Kattan MW, Karpeh MS, Mazumdar M, et al. Postoperative nomogram for disease-specific survival after an $\mathrm{RO}$ resection for gastric carcinoma. J Clin Oncol 2003;21:3647-3650.

31. Sterne JAC, White IR, Carlin JB, et al. Multiple imputation for missing data in epidemiological and clinical research: potential and pitfalls. BMJ 2009;338:b2393.

32. Steyerberg EW. Clinical Prediction Models: A Practical Approach to Development, Validation, and Updating. New York, NY: Springer Science+Business Media; 2009

33. van Kleef JJ, van den Boorn HG, Verhoeven RHA et al. External validation of the Dutch SOURCE survival prediction model in Belgian metastatic oesophageal and gastric cancer patients. Cancers (Basel) 2020;12:834.

34. Zipkin DA, Umscheid CA, Keating NL, et al. Evidence-based risk communication: a systematic review. Ann Intern Med 2014;161:270-280.

See JNCCN.org for supplemental online content. 
Supplemental online content for:

\section{SOURCE: Prediction Models for Overall Survival in Patients With Metastatic and Potentially Curable Esophageal and Gastric Cancer}

Héctor G. van den Boorn, MSc; Ameen Abu-Hanna, PhD; Nadia Haj Mohammad, MD, PhD;

Maarten C.C.M. Hulshof, MD, PhD; Suanne S. Gisbertz, MD, PhD; Bastiaan R. Klarenbeek, MD, PhD; Marije Slingerland, MD, PhD; Laurens V. Beerepoot, MD, PhD; Tom Rozema, MD; Mirjam A.G. Sprangers, PhD; Rob H.A. Verhoeven, PhD; Martijn G.H. van Oijen, PhD; Koos H. Zwinderman, PhD; and Hanneke W.M. van Laarhoven, MD, PhD

J Natl Compr Canc Netw 2021;19(4):403-410

eFigure 1: Kaplan-Meier Curves for the 4 Cohorts

eFigure 2: Nomogram of Model for Gastric Cancer: Metastatic

eFigure 3: Nomogram of Model for Esophageal Cancer: Metastatic

eFigure 4: Nomogram of Model for Gastric Cancer: Potentially Curable

eFigure 5: Nomogram of Model for Esophageal Cancer: Potentially Curable

eFigure 6: Calibration Plots for the 4 SOURCE Models

eTable 1: Expanded Patient Characteristics

eTable 2: Parameters for Esophageal: Metastatic Model

eTable 3: Parameters for Esophageal: Potentially Curable Model

eTable 4: Parameters for Gastric: Metastatic Model

eTable 5: Parameters for Gastric: Potentially Curable Model 
A

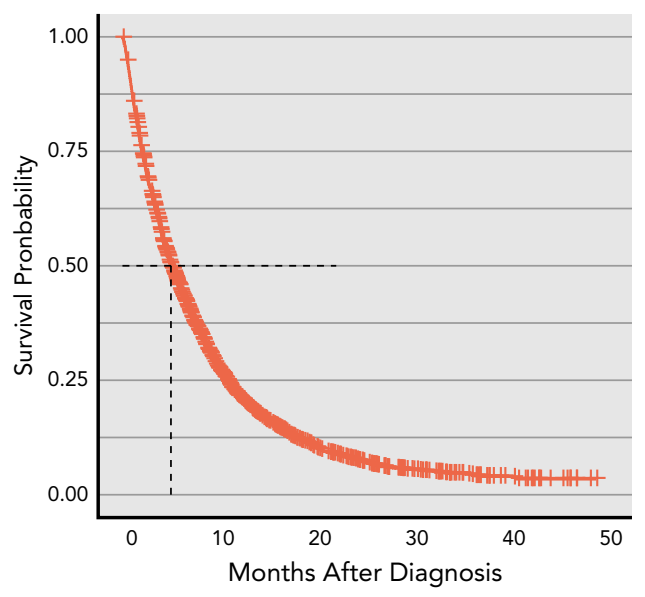

C

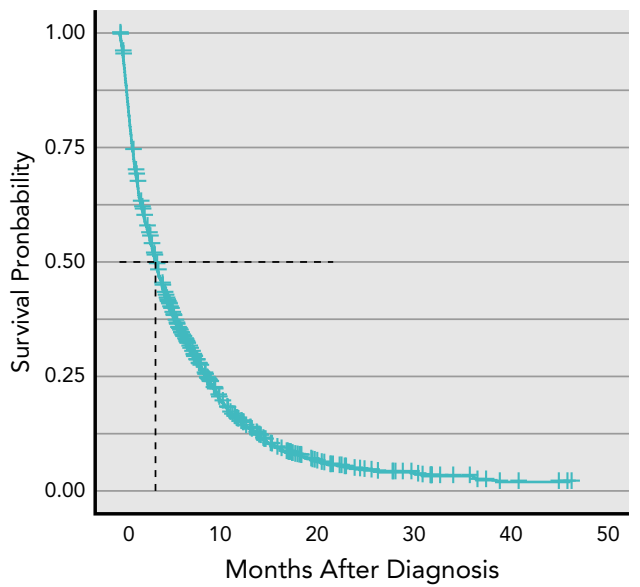

B

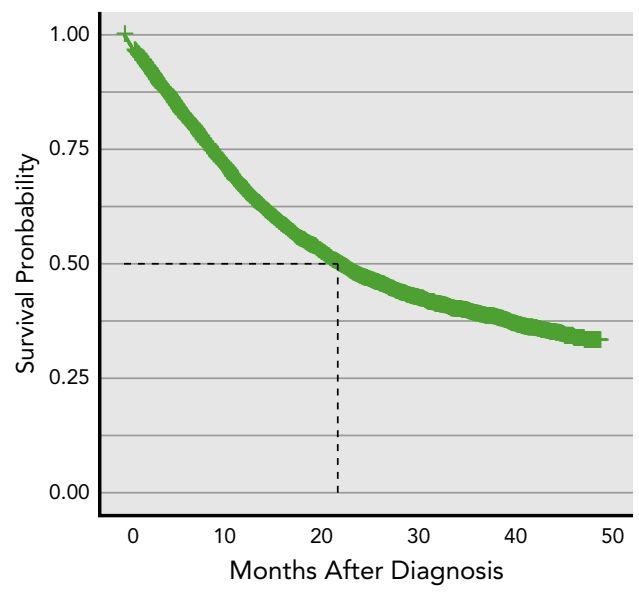

D

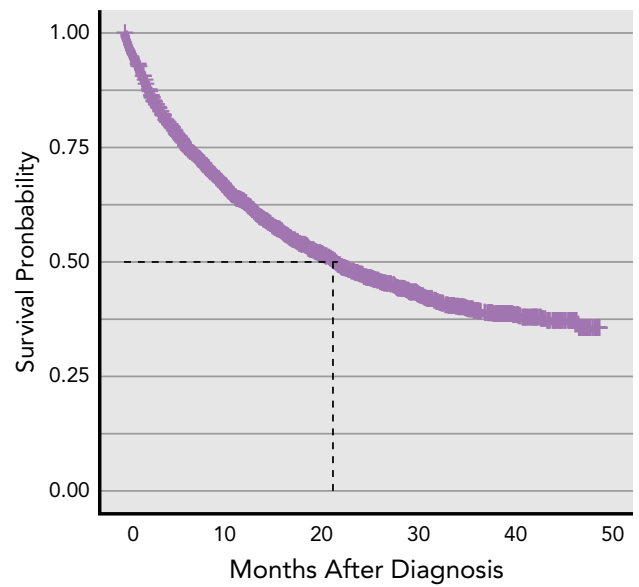

eFigure 1. Kaplan-Meier curves for the 4 cohorts: (A) esophagus, metastatic; (B) esophagus, potentially curable; (C) gastric, metastatic; and (D) gastric, potentially curable. 


\section{Gastric (Metastatic)}

\begin{tabular}{|c|c|c|c|c|c|}
\hline \multirow[b]{2}{*}{ Points } & 0 & \multicolumn{2}{|c|}{10} & \multicolumn{2}{|c|}{20} \\
\hline & ᄂ & , ـــ & $\perp$ & ـــــ & 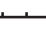 \\
\hline \multirow[t]{3}{*}{ Age, y } & $\Gamma$ & 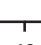 & & $T$ & $\square$ \\
\hline & 20 & 40 & 60 & 80 & 100 \\
\hline & & & 1 & & 2 \\
\hline WHO performance status & $\Gamma$ & 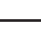 & & 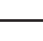 & ب \\
\hline
\end{tabular}

Albumin, g/L

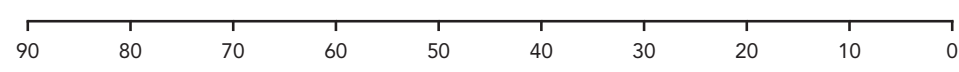

Hemoglobin, mmol/L

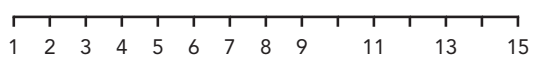

LDH, U/L

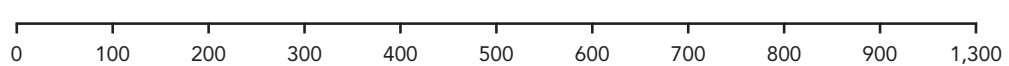

cT stage

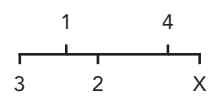

Differentiation grade

G3

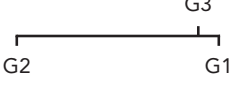

Liver metastasis

Yes

No

Metastatic sites, $\mathrm{n}$

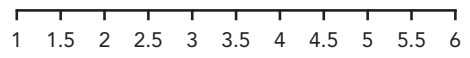

Initial treatment

Other Stent

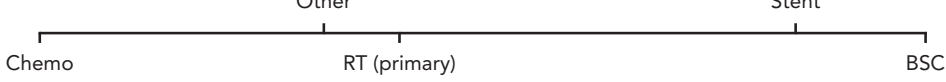

Total points

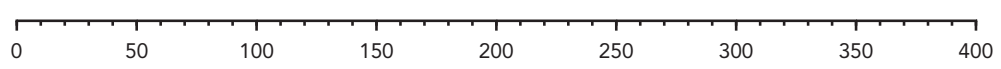

6-month survival

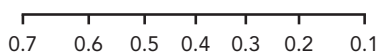

1-year survival

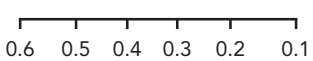

eFigure 2. Nomogram of model for gastric cancer: metastatic.

Abbreviations: BSC, best supportive care; chemo, chemotherapy; G, grade; LDH, lactate dehydrogenase; RT, radiotherapy. 


\section{Esophageal (Metastatic)}

Points

\begin{tabular}{lcccccccccc}
0 & 10 & 20 & 30 & 40 & 50 & 60 & 70 & 80 & 90 & 100 \\
\hline
\end{tabular}

Age, y

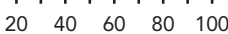

Sex

$$
\text { Female }
$$

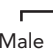

$\mathrm{BMI}, \mathrm{kg} / \mathrm{m}^{2}$

\section{तामा1म11}

$50 \quad 3520$

WHO performance status

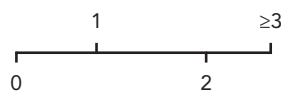

Albumin, g/L

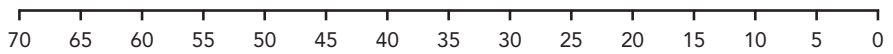

$\mathrm{LDH}, \mathrm{U} / \mathrm{L}$

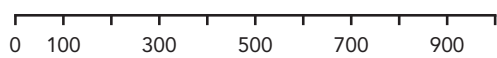

Creatinine, $\mu \mathrm{mol} / \mathrm{L}$

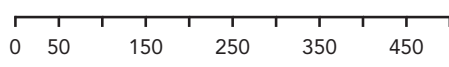

cT stage

$\begin{array}{ll}2 & x \\ 3 & 1\end{array}$

$\mathrm{cN}$ stage

13

$\overbrace{0}^{1}$

G1

Differentiation grade

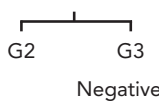

HER2 status

Only distance LN

metastasis
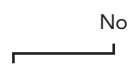

Yes

Peritoneal metastasis

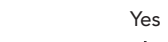

No

Metastatic sites, n

Initial treatment

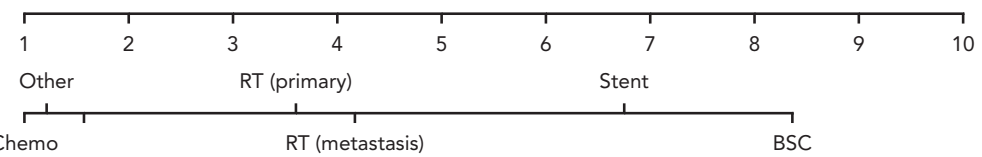

Total points

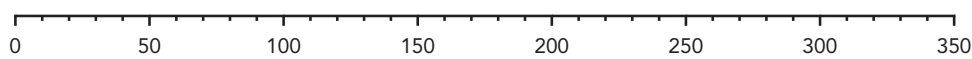

6-month survival

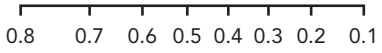

1-year survival

\begin{tabular}{llllllllll}
\hline & 1 & 1 & 1 & 1 & 1 & 1 & 1 & 1
\end{tabular}

eFigure 3. Nomogram of model for esophageal cancer: metastatic.

Abbreviations: BMI, body mass index; BSC, best supportive care; chemo, chemotherapy; G, grade; LDH, lactate dehydrogenase; LN, lymph node; RT, radiotherapy. 


\section{4 - van den Boorn et al}

\section{Gastric (Potentially Curable)}

Points

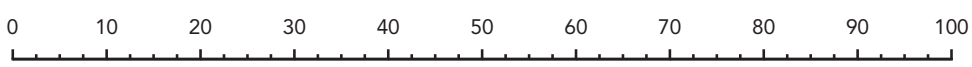

Age, $y$

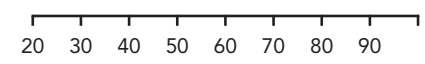

Sex

Male

Female

BMI, $\mathrm{kg} / \mathrm{m}^{2}$

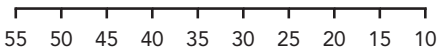

Albumin, g/L

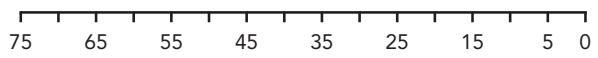

$\mathrm{LDH}, \mathrm{U} / \mathrm{L}$

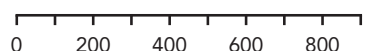

cT stage

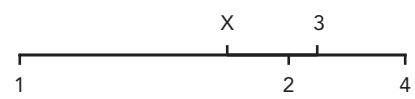

$\mathrm{cN}$ stage

Tumour topography

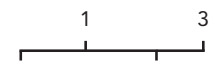

0

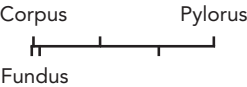

Fundus

G1

Differentiation grade

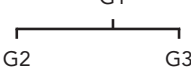

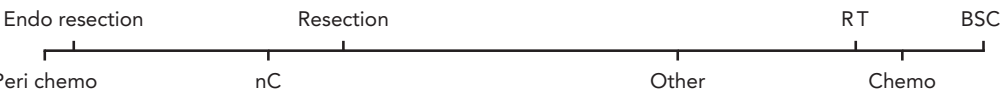

Total points

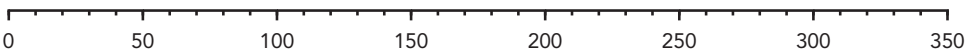

1-year survival

2-year survival

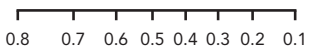

\begin{tabular}{lllllllll}
\hline & 1 & 1 & 1 & 1 & 1 & 1
\end{tabular}

3-year survival

\begin{tabular}{llllllllll}
\hline & & & & & 1 & 1 & 1 & 1 & 1 \\
0.8 & 0.7 & 0.6 & 0.5 & 0.4 & 0.3 & 0.2 & 0.1
\end{tabular}

4-year survival

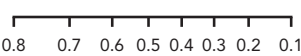

eFigure 4. Nomogram of model for gastric cancer: potentially curable.

Abbreviations: BMI, body mass index; BSC, best supportive care; chemo, chemotherapy; endo, endoscopic; G, grade; LDH, lactate dehydrogenase; $\mathrm{nC}$, neoadjuvant chemotherapy; peri, perioperative; RT, radiotherapy. 


\section{Esophageal (Potentially Curable)}

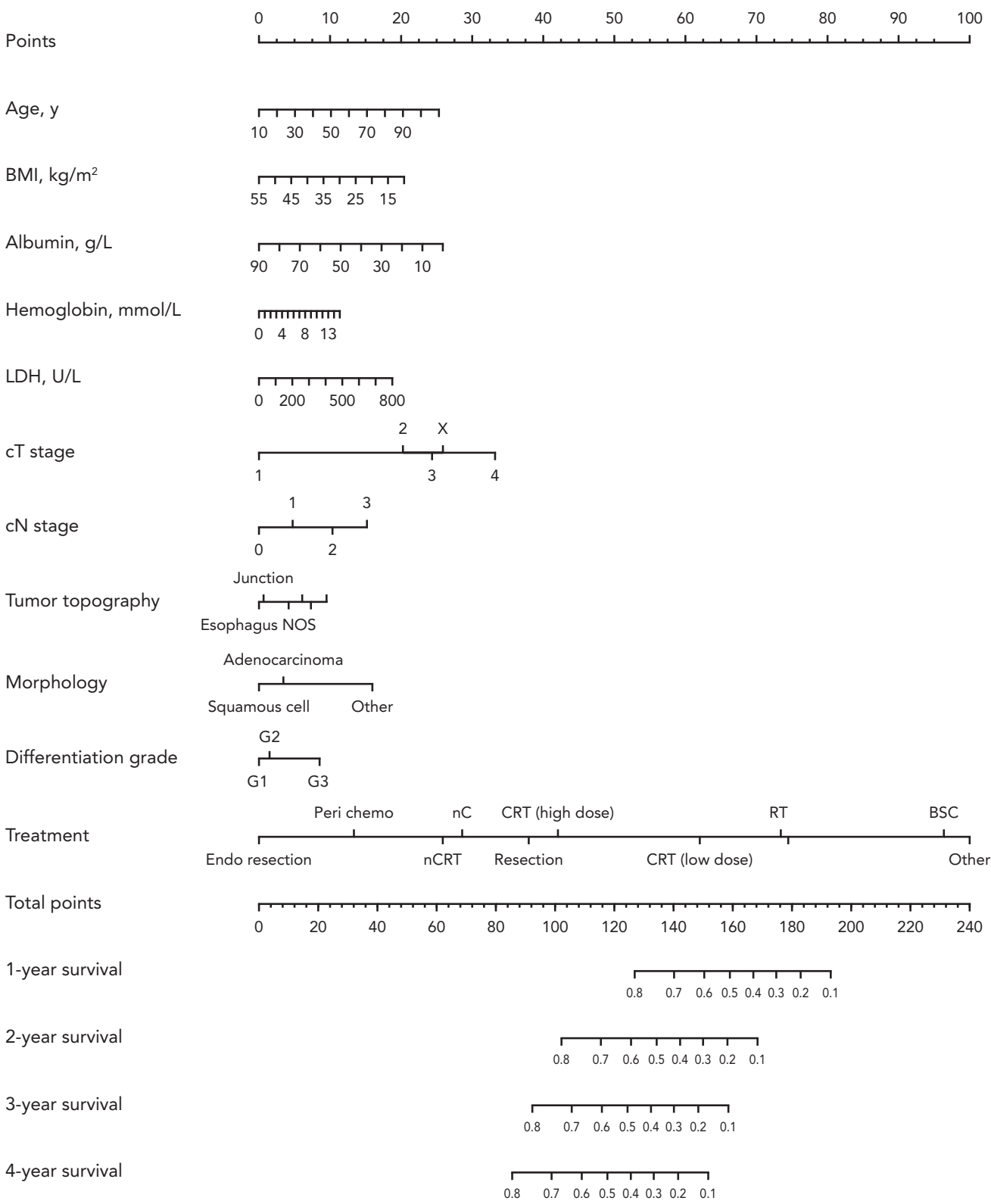

eFigure 5. Nomogram of model for esophageal cancer: potentially curable.

Abbreviations: BMI, body mass index; BSC, best supportive care; chemo, chemotherapy; CRT, chemoradiotherapy; endo, endoscopic; G, grade; LDH, lactate dehydrogenase; $\mathrm{nC}$, neoadjuvant chemotherapy; $\mathrm{nCRT}$, neoadjuvant chemoradiotherapy; NOS, not otherwise specified; peri, perioperative; RT, radiotherapy. 
A

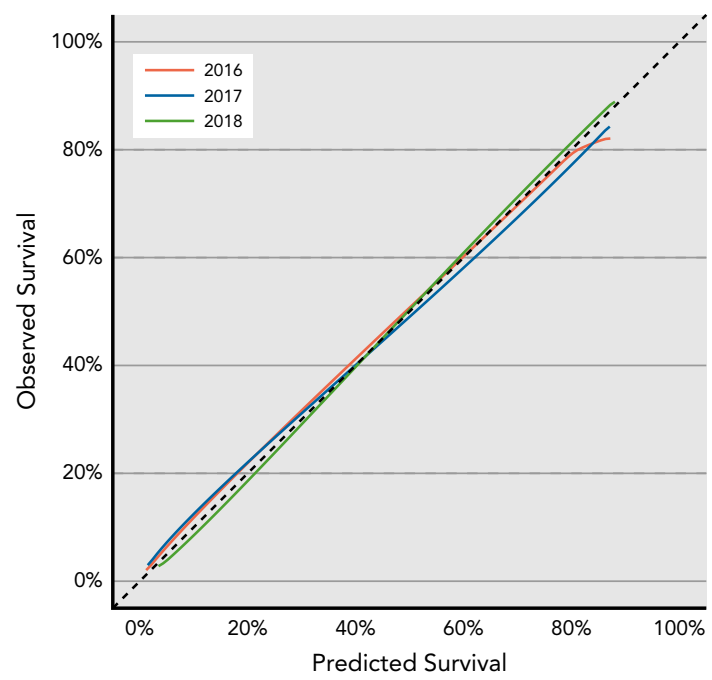

C

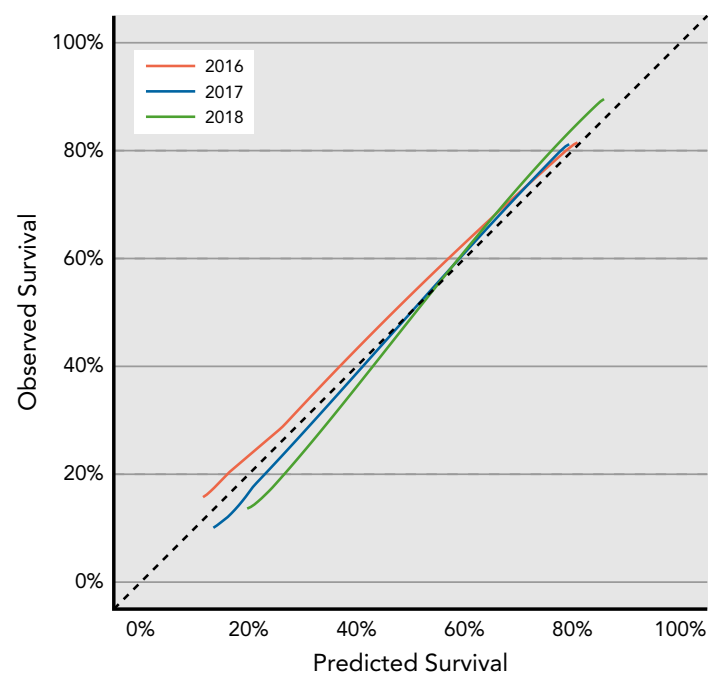

B

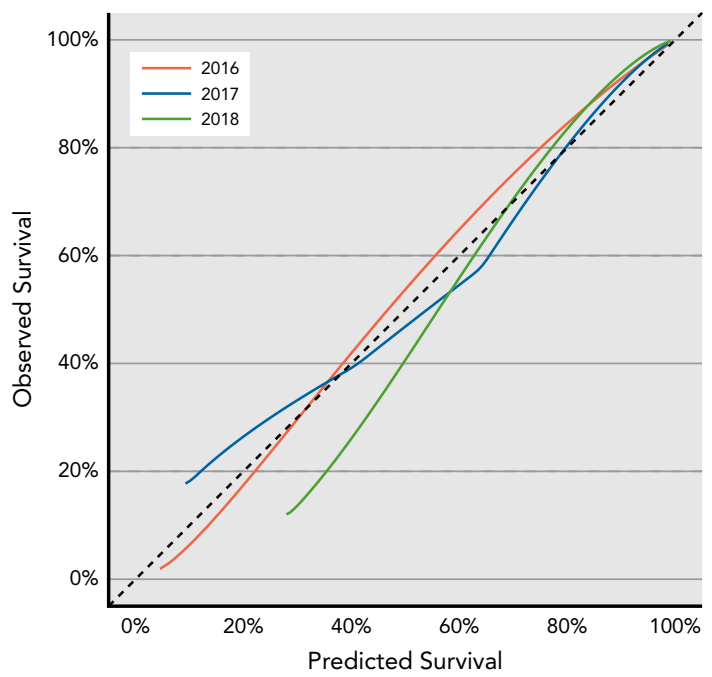

D

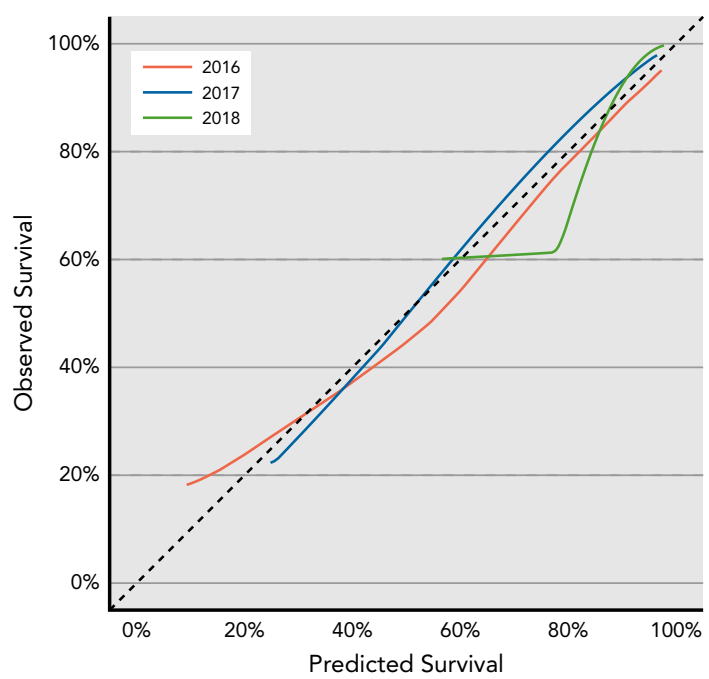

eFigure 6. Calibration plots for the 4 SOURCE models by year: (A) esophagus, metastatic; (B) esophagus, potentially curable; (C) gastric, metastatic; and (D) gastric, potentially curable. 
eTable 1. Expanded Patient Characteristics

\begin{tabular}{|c|c|c|c|c|}
\hline & \multicolumn{2}{|c|}{$\begin{array}{c}\text { Esophageal Cancer } \\
\text { n (\%) }\end{array}$} & \multicolumn{2}{|c|}{$\begin{array}{c}\text { Gastric Cancer } \\
\text { n (\%) }\end{array}$} \\
\hline & Metastatic & Potentially Curable & Metastatic & Potentially Curable \\
\hline Median overall survival (IQR), mo & $5.3(5.0-5.6)$ & $22.7(21.7-23.8)$ & $4.3(4.0-4.6)$ & $22.8(21.2-25.8)$ \\
\hline Age, mean (SD), y & $67.40(10.38)$ & $69.59(10.49)$ & $68.95(12.20)$ & 72.19 (12.19) \\
\hline Female & $703(21.5)$ & $1,762(27.5)$ & $642(39.4)$ & $822(39.9)$ \\
\hline Weight, mean (SD), kg & $77.26(16.03)$ & $77.80(17.05)$ & $73.69(15.32)$ & $73.96(15.31)$ \\
\hline $\mathrm{BMI}$, mean (SD), $\mathrm{kg} / \mathrm{m}^{2}$ & $25.10(4.46)$ & $25.59(4.74)$ & $24.94(4.57)$ & $25.26(4.51)$ \\
\hline Missing & $1,517(46.4)$ & $2,410(37.6)$ & $763(46.8)$ & $913(44.3)$ \\
\hline 1 & $906(27.7)$ & $1,900(29.7)$ & $397(24.4)$ & $518(25.1)$ \\
\hline 2 & 355 (10.9) & $521(8.1)$ & 181 (11.1) & $146(7.1)$ \\
\hline$\geq 3$ & $192(5.9)$ & $195(3.0)$ & $100(6.1)$ & $72(3.5)$ \\
\hline \multicolumn{5}{|l|}{ ASA performance score } \\
\hline Missing & $3,002(91.8)$ & $3,340(52.1)$ & $1,444(88.6)$ & $826(40.1)$ \\
\hline 1 & $42(1.3)$ & $291(4.5)$ & $23(1.4)$ & $81(3.9)$ \\
\hline 2 & $159(4.9)$ & $1,981(30.9)$ & $108(6.6)$ & 699 (33.9) \\
\hline 3 & $65(2.0)$ & $767(12.0)$ & $51(3.1)$ & $427(20.7)$ \\
\hline 4 & $3(0.09)$ & $26(0.4)$ & $3(0.2)$ & $27(1.3)$ \\
\hline Creatinine, mean (SD), $\mu \mathrm{mol} / \mathrm{L}$ & $84.80(32.06)$ & $85.70(32.06)$ & 83.99 (35.89) & $85.54(33.80)$ \\
\hline Missing & $370(11.3)$ & 925 (14.4) & $167(10.3)$ & $284(13.8)$ \\
\hline \multicolumn{5}{|l|}{ cT stage } \\
\hline 1 & $16(0.5)$ & $347(5.4)$ & $3(0.2)$ & $103(5.0)$ \\
\hline 2 & $1,186(36.3)$ & $1,891(29.5)$ & $453(27.8)$ & 773 (37.5) \\
\hline 3 & $964(29.5)$ & $3,154(49.2)$ & $353(21.7)$ & $483(23.4)$ \\
\hline 4 & $240(7.3)$ & $109(1.7)$ & 281 (17.2) & $91(4.4)$ \\
\hline$x$ & $865(26.4)$ & $904(14.1)$ & $539(33.1)$ & $610(29.6)$ \\
\hline \multicolumn{5}{|l|}{$\mathrm{cN}$ stage } \\
\hline 0 & $596(18.2)$ & $3,210(50.1)$ & $701(43.0)$ & $1,457(70.7)$ \\
\hline 1 & $1,062(32.5)$ & $2,030(31.7)$ & $421(25.8)$ & $394(19.1)$ \\
\hline 2 & $1,237(37.8)$ & $1,003(15.7)$ & $430(26.4)$ & $181(8.8)$ \\
\hline 3 & $376(11.5)$ & $162(2.5)$ & $77(4.7)$ & $28(1.4)$ \\
\hline
\end{tabular}




\section{eTable 1. Expanded Patient Characteristics (cont.)}

\begin{tabular}{|c|c|c|c|c|}
\hline & \multicolumn{2}{|c|}{$\begin{array}{c}\text { Esophageal Cancer } \\
\mathbf{n}(\%)\end{array}$} & \multicolumn{2}{|c|}{$\begin{array}{c}\text { Gastric Cancer } \\
\mathbf{n}(\%)\end{array}$} \\
\hline & Metastatic & Potentially Curable & Metastatic & Potentially Curable \\
\hline Lower thoracic & $1,998(61.1)$ & $4,013(62.7)$ & - & - \\
\hline Upper thoracic & $73(2.2)$ & $303(4.7)$ & - & - \\
\hline Esophagus NOS & $127(3.9)$ & $191(3.0)$ & - & - \\
\hline Junction & 715 (21.9) & $922(14.4)$ & - & - \\
\hline Overlapping gastric lesion & - & - & $487(29.9)$ & $324(15.7)$ \\
\hline Fundus & - & - & $70(4.3)$ & $75(3.6)$ \\
\hline Gastric NOS & - & - & $183(11.2)$ & $202(9.8)$ \\
\hline \multicolumn{5}{|l|}{ Morphology } \\
\hline Adenocarcinoma & $2,720(83.2)$ & $4,669(72.9)$ & $1,611(98.9)$ & $2,042(99.1)$ \\
\hline Squamous cell & $483(14.8)$ & $1,681(26.2)$ & $0(0)$ & $0(0)$ \\
\hline Other & $68(2.1)$ & $55(0.9)$ & $18(1.1)$ & $18(0.9)$ \\
\hline \multicolumn{5}{|l|}{ Differentiation grade } \\
\hline Missing & $1,157(35.4)$ & $1,644(25.7)$ & $724(44.4)$ & $544(26.4)$ \\
\hline 1 & $98(3.0)$ & $342(5.3)$ & $19(1.2)$ & $44(2.1)$ \\
\hline 2 & $774(23.7)$ & $2,363(36.9)$ & $205(12.6)$ & $481(23.3)$ \\
\hline No & $3,023(92.4)$ & - & $1,599(98.2)$ & - \\
\hline Yes & $248(7.6)$ & - & $30(1.8)$ & - \\
\hline \multicolumn{5}{|l|}{ Intrathoracic LN metastasis } \\
\hline No & $3,148(96.2)$ & - & $1,580(97.0)$ & - \\
\hline Yes & $123(3.8)$ & - & $49(3.0)$ & - \\
\hline \multicolumn{5}{|l|}{ Intra-abdominal LN metastasis } \\
\hline No & $2,659(81.3)$ & - & $1,409(86.5)$ & - \\
\hline Yes & $612(18.7)$ & - & $220(13.5)$ & - \\
\hline \multicolumn{5}{|l|}{ Only distant $\mathrm{LN}$ metastasis } \\
\hline No & $2,788(85.2)$ & - & $1,489(91.4)$ & - \\
\hline Yes & $483(14.8)$ & - & $140(8.6)$ & - \\
\hline
\end{tabular}

(continued on next page) 


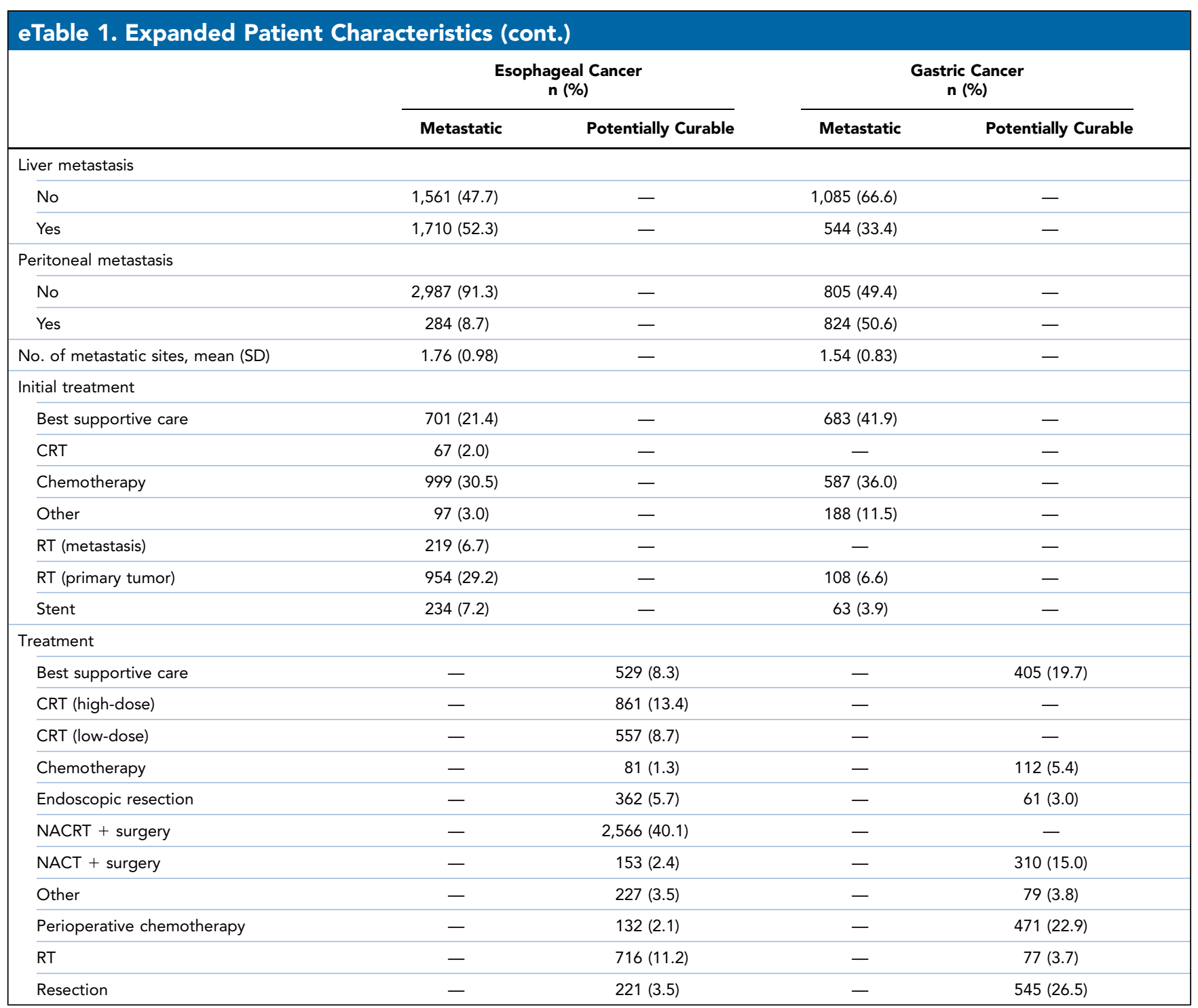

Abbreviations: ASA, American Society of Anesthesiologists; BMI, body mass index; CRT, chemoradiotherapy; IQR, interquartile range; LN, lymph node; NACRT, neoadjuvant chemoradiotherapy; NACT, neoadjuvant chemotherapy; NOS, not otherwise specified, RT, radiotherapy. 


\section{eTable 2. Parameters for Esophageal Cancer:} Metastatic Model

\begin{tabular}{|c|c|}
\hline Predictor & HR (95\% Cl) \\
\hline Age & 1.005 (1.001-1.009) \\
\hline \multicolumn{2}{|l|}{ Sex } \\
\hline Male & Ref \\
\hline Female & $1.100(1.001-1.208)$ \\
\hline BMI, $\mathrm{kg} / \mathrm{m}^{2}$ & $0.994(0.986-1.002)$ \\
\hline \multicolumn{2}{|l|}{ WHO performance status } \\
\hline 0 & Ref \\
\hline 1 & $1.168(1.068-1.278)$ \\
\hline 2 & $1.446(1.279-1.634)$ \\
\hline$\geq 3$ & $1.639(1.413-1.902)$ \\
\hline Albumin, g/L & $0.976(0.971-0.982)$ \\
\hline Lactate dehydrogenase, U/L & $1.001(1.001-1.001)$ \\
\hline Creatinine, $\mu \mathrm{mol} / \mathrm{L}$ & $1.002(1.000-1.003)$ \\
\hline \multicolumn{2}{|l|}{ cT stage } \\
\hline 1 & Ref \\
\hline 2 & $0.853(0.504-1.444)$ \\
\hline 3 & $0.797(0.470-1.351)$ \\
\hline 4 & $1.097(0.639-1.883)$ \\
\hline$x$ & $1.024(0.604-1.734)$ \\
\hline \multicolumn{2}{|l|}{ cN stage } \\
\hline 0 & Ref \\
\hline 1 & $1.031(0.923-1.151)$ \\
\hline 2 & $1.232(1.104-1.374)$ \\
\hline 3 & $1.264(1.092-1.462)$ \\
\hline
\end{tabular}

(continued)

\section{eTable 2. Parameters for Esophageal Cancer:} Metastatic Model (cont.)

\section{Predictor}

HR $(95 \% \mathrm{Cl})$

Differentiation grade

1 Ref

$20.903(0.776-1.050)$

$3 \quad 1.116(0.968-1.288)$

HER2 status

Negative Ref

Positive

$0.832(0.761-0.909)$

Only distant $\mathrm{LN}$ metastasis

No Ref

Yes $0.823(0.732-0.925)$

Peritoneal metastasis

No Ref

Yes $1.248(1.090-1.428)$

Number of metastatic sites $\quad 1.225(1.175-1.276)$

Initial treatment

Best supportive care Ref

Chemotherapy $0.225(0.200-0.252)$

Chemoradiotherapy $0.252(0.189-0.338)$

RT (primary tumor) $0.381(0.342-0.424)$

RT (metastasis) $\quad 0.427(0.362-0.505)$

Stent $0.721(0.620-0.839)$

Other $\quad 0.235(0.181-0.304)$

Abbreviations: BMI, body mass index; HR, hazard ratio; LN, lymph node; RT, radiotherapy. 


\section{eTable 3. Parameters for Esophageal Cancer:} Potentially Curable Model

\section{Predictor}

$\mathrm{HR}(95 \% \mathrm{Cl})$

Age 1.009 (1.005-1.013)

$\mathrm{BMI}, \mathrm{kg} / \mathrm{m}^{2} \quad 0.984(0.977-0.992)$

Albumin, $\mathrm{g} / \mathrm{L}$ $0.990(0.984-0.996)$

Hemoglobin, $\mathrm{mmol} / \mathrm{L}$ $1.029(1.001-1.058)$

Lactate dehydrogenase, U/L 1.001 (1.000-1.001)

cT stage

\begin{tabular}{cc}
\hline 1 & Ref \\
\hline 2 & $2.042(1.548-2.693)$ \\
\hline 3 & $2.360(1.786-3.117)$ \\
\hline 4 & $3.225(2.257-4.610)$ \\
\hline$X$ & $2.490(1.883-3.294)$
\end{tabular}

$\mathrm{cN}$ stage

0 Ref

1

$1.182(1.083-1.290)$

2

1.440 (1.294-1.602)

3

1.708 (1.391-2.099)

Tumor topography

Lower thoracic

Ref

Upper thoracic

$1.117(0.934-1.336)$

Midthoracic

$1.070(0.949-1.206)$

Overlapping lesion

1.207 (0.926-1.573)

Esophagus NOS

$0.863(0.695-1.072)$

Junction $0.883(0.785-0.994)$

Morphology

Adenocarcinoma

Ref

Squamous cell

0.886 (0.799-0.982)

Other

1.555 (1.104-2.189)

Differentiation grade

1

Ref

2

$1.054(0.898-1.236)$

3

$1.351(1.149-1.588)$

Treatment

\begin{tabular}{lc} 
Best supportive care & Ref \\
\hline NACRT + surgery & $0.083(0.072-0.096)$ \\
\hline NACT + surgery & $0.092(0.067-0.125)$ \\
\hline Chemoradiotherapy (low-dose) & $0.298(0.256-0.346)$ \\
\hline Chemoradiotherapy (high-dose) & $0.147(0.127-0.171)$ \\
\hline Resection & $0.128(0.099-0.165)$ \\
\hline Perioperative chemotherapy & $0.054(0.036-0.081)$ \\
\hline Chemotherapy & $0.462(0.349-0.611)$ \\
\hline Radiotherapy & $0.445(0.392-0.506)$ \\
\hline Endoscopic resection & $0.033(0.023-0.048)$ \\
\hline Other & $1.136(0.962-1.342)$
\end{tabular}

Abbreviations: BMI, body mass index; HR, hazard ratio; NACRT, neoadjuvant chemoradiotherapy; NACT, neoadjuvant chemotherapy; NOS, not otherwise specified. 


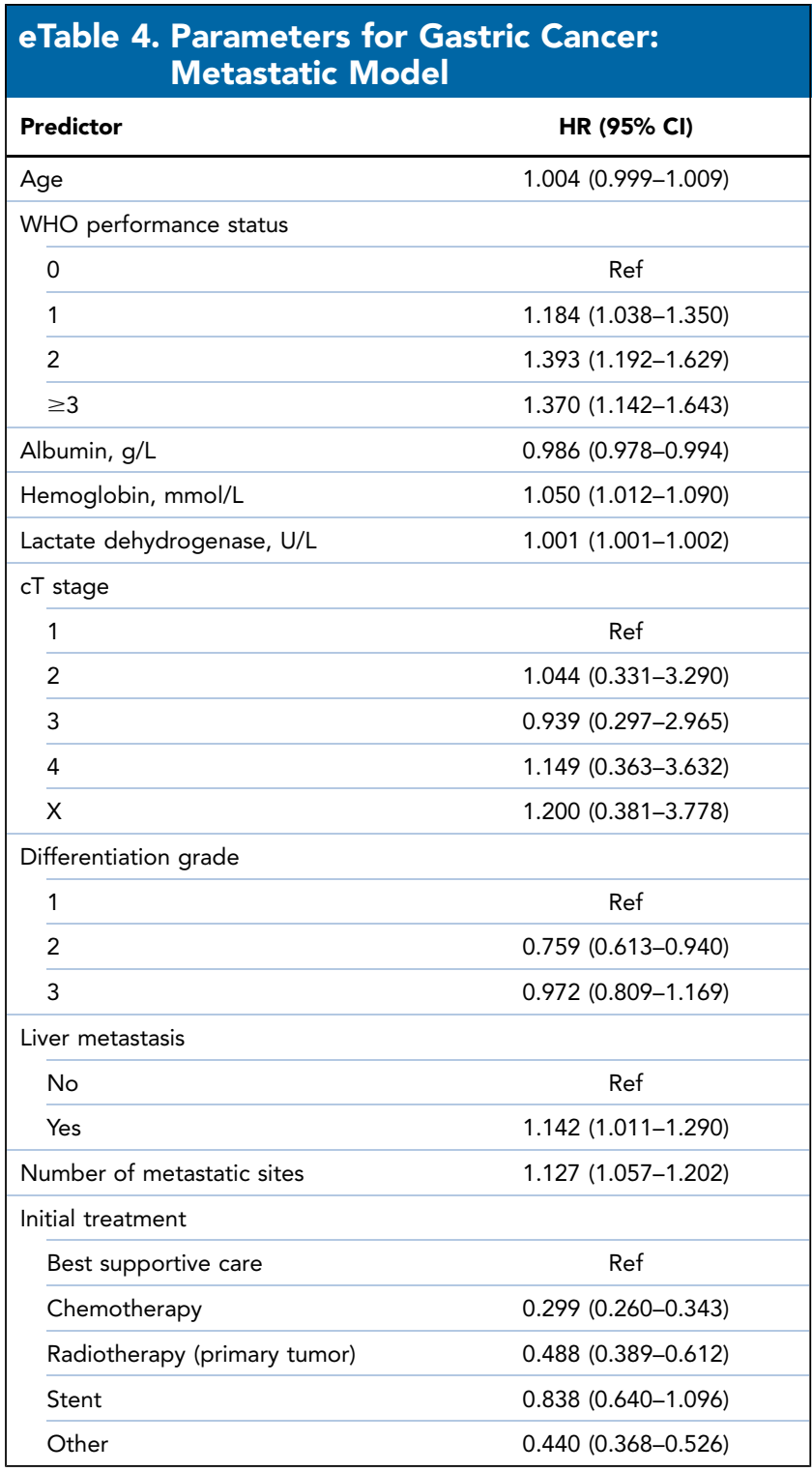

Abbreviation: HR, hazard ratio.

\section{eTable 5. Parameters for Gastric Cancer:} Potentially Curable Model

\section{Predictor}

Age

Sex

$$
\text { Male }
$$

Female

BMI, $\mathrm{kg} / \mathrm{m}^{2}$

Albumin, $\mathrm{g} / \mathrm{L}$

Lactate dehydrogenase, U/L

cT stage

1

2

3

4

$\mathrm{X}$

$\mathrm{cN}$ stage

0

1

1

2

3

Tumor topography

Antrum pylori

Fundus

Corpus

Pylorus

Overlapping lesion

Gastric NOS

Differentiation grade

1

2

3

Treatment

Best supportive care

NACT + surgery

Resection

Perioperative chemotherapy

Chemotherapy

Radiotherapy

Endoscopic resection

Other

Abbreviations: $\mathrm{BMI}$, body mass index; HR, hazard ratio: NACT, neoadjuvant

chemotherapy; NOS, not otherwise specified.

\section{$\mathrm{HR}(95 \% \mathrm{Cl})$}

$1.012(1.004-1.019)$

Ref

$0.843(0.740-0.960)$

$0.978(0.965-0.992)$

$0.982(0.972-0.992)$

$1.001(1.000-1.002)$

Ref

$1.909(1.195-3.051)$

$2.044(1.262-3.312)$

$2.526(1.475-4.327)$

$1.647(1.030-2.633)$

Ref

$1.169(0.993-1.376)$

1.386 (1.109-1.732)

$1.551(0.938-2.564)$

\section{Ref}

0.981 (0.689-1.397)

$0.985(0.830-1.170)$

$1.520(1.190-1.941)$

$1.332(1.116-1.589)$

$1.156(0.931-1.437)$

Ref

$0.793(0.602-1.046)$

$1.172(0.912-1.506)$

Ref

$0.179(0.141-0.228)$

$0.215(0.178-0.259)$

$0.105(0.081-0.135)$

$0.823(0.636-1.064)$

$0.736(0.564-0.959)$

$0.112(0.056-0.224)$

$0.479(0.350-0.657)$ 